Andrzej Kraslawski and Ilkka Turunen (Editors) Proceedings of the $23^{\text {rd }}$ European Symposium on Computer Aided Process Engineering - ESCAPE 23 June 9-12, 2013, Lappeenranta, Finland,

(C) 2013 Elsevier B.V. All rights reserved.

\title{
Towards supply chain sustainability: balancing costs with environmental and social impacts
}

\author{
Bruna Mota ${ }^{\mathrm{a}}$, Maria Isabel Gomes ${ }^{\mathrm{b}}$, Ana Paula Barbosa-Póvoa ${ }^{\mathrm{a}}$ \\ ${ }^{a}$ CEG-IST, Instituto Superior Técnico, Universidade Técnica de Lisboa, Av. Rovisco \\ Pais, 1049-001 Lisboa, Portugal \\ ${ }^{b}$ Centro de Matematica e Aplicações, Faculdade de Ciências e Tecnologia, \\ Universidade Nova de Lisboa, Monte de Caparica, 2829-516 Caparica, Portugal
}

\begin{abstract}
This work presents a multi-objective optimization methodology that accounts for economic, environmental and social concerns in a supply chain with reverse flows. Environmental impact assessment is considered through the use of Recipe 2008. A social benefit indicator is developed where the creation of employment in less developed regions is preferred. The multi-objective approach is used to reach a solution of compromise between the three sustainability pillars. The model is applied to a case study developed in collaboration with a Portuguese company, leader in battery production.
\end{abstract}

Keywords: supply chain sustainability, environmental impact assessment, social impact assessment, multi-objective approach

\section{Introduction}

The growing awareness on the impact that human activities may have on the environment is transforming industry practices. Costumers are now highly interested in knowing how the product bought is produced, how it is brought to them, and what is the overall impact it has on the world, meaning that - if working conditions are being respected, if $\mathrm{CO}_{2}$ emissions are being controlled, and if end-of-life products are being handled. Even though legislation is forcing industries to work towards sustainability, industry practitioners are realizing that going beyond legislation compliance will very likely bring them a significant competitive advantage. Taking the lead in sustainability practices can, for example, improve the company's image, creating brand preference and increasing profits. However, achieving sustainability is a challenging task. Choices previously based on cost/quality, such as selecting suppliers or distribution channels, can have very different outcomes when overall sustainability is considered. So it is important to understand the supply chain as a whole, as well as the entire life cycle of the product, from cradle to cradle. This brings us to closed loop supply chains where reverse flows must be considered when designing and planning a supply chain as they not only allow the supply chain to be more sustainable, but also help lowering costs, and improving coordination and customer service (Guide et al. 2003). Additionally, overall environmental and social sustainability must also be addressed. Literature on environmental impacts is diverse, however life cycle analysis (LCA) has been described as the most scientifically reliable method currently available for studying and evaluating the environmental impacts of a certain product or process (Ness et al. 2007). This methodology has and continues being used within the supply chain context using many different methods. Eco-indicator 99 is one of the most widely used methods (Hugo et al. 2005, Guillén-Gosálbez et al. 2009, Duque et al. 2010, Pinto-Varela et al. 2011), but 
others such as IMPACT 2002+ have also been used (Bojarski et al. 2009). All present pros and cons but ReCiPe 2008 seems to be the most consensual method for LCA (JRC 2011). Literature on social impacts is not as diverse, mainly due to the lack of data and quantifiable social indicators (Brent et al. 2006). However, since the release of the Guidelines for Social Impact Assessment of Products (UNEP-SETAC, 2009), more case-studies have emerged. Still, the majority of the developed indicators are either based on passed occurrences or simply do not fit into supply chain design and planning. A research gap is also found in assessing the three pillars of sustainability in an integrated approach with the necessary trade-offs being considered. This work aims to be a step forward in this direction by providing a model for the design and planning of closed loop supply chains, which incorporates the three pillars of sustainability. The main objective is to help industry practitioners, as well as policy makers, in decision making by delivering solutions of compromise.

This paper is structured as follows. In section 2 the problem is defined and the developed model is characterized. Section 3 presents a case study where the proposed model is applied to a Portuguese company, leader in battery manufacturing. Section 4 includes final remarks and future work.

\section{Problem definition}

The problem addressed in this work aims at determining the supply chain structure along with planning decisions that minimizes costs, minimizes environmental impact and maximizes social benefit, in a solution of compromise. The problem is modeled through a Mixed Integer Linear Programming (MILP) and is based on the generic modeling framework developed by Salema et al. (Salema et al. 2010), that uses a graph approach for the design and planning of supply chains with reverse flows. The decisions at the design level are taken for a given time horizon (e.g. 3 years), whereas for the planning level two-interconnected time scales are considered within that time horizon: a macroscale (e.g. a year) that gives us the time horizon discretization, where demand and return values must be satisfied, and a microscale (e.g. a month) that allows for more detailed planning on attaining this satisfaction. The environmental assessment of the supply chain is introduced using ReCiPe 2008 (Goedkoop et al. 2009) on the main activities with potential environmental impact (e.g. production, transportation and installation of entities). The environmental model is designed to allow access to both midpoint and endpoint results, making it possible to identify the major sources of pollution so that alternatives can be studied. It also permits access to results without the contribution of normalization and weighting factors, allowing an analysis of the environmental impact in each category in comprehensible units. To address the social impact, a social benefit indicator was developed that favors entities to be located in less developed regions, as described in equation (1)

$S B=\sum_{i \in I} \sum_{r \in R} \mu_{r} \times l_{i r} \times w_{i}$

where $w_{i}$ is the number of jobs created due to installation of entity $i, l_{i r}$ is a parameter that equals 1 if entity $i$ belongs to region $\mathrm{r}$, and 0 otherwise, and $\mu_{r}$ represents a regional factor, which can assume different values according to the intended purpose of the study (e.g. unemployment rate, population density or income distribution). It should be noted that this social benefit indicator comprises not only job creation but also, although indirectly, environmental impact and life quality (e.g. services' accessibility, health), aiming to achieve overall benefit (e.g. for the country) and not for the company in particular. 
Overall, given a) a possible superstructure for the location of the supply chain entities; b) the investment costs; c) products' bills of materials; d) the relation between forward and reverse products; e) travel time between each pair of interacting network agents; f) the minimum disposal fraction; g) the minimum usage time for each return product, $h$ ) forward product return fractions; i) the maximum and minimum flow capacities; $j$ ) the maximum and minimum acquisition and production capacities; $\mathrm{k}$ ) the maximum storage capacities; 1) the initial stock levels, m) the costs with salaries; n) each facility environmental impact; o) the unit transportation environmental impact; $p$ ) the environmental impact of production processes; q) the social benefit associated to each facility; and for each macroperiod and product, r) customer's demand volume: and s) the unit penalty costs for non-satisfied demand and return, and for each microperiod and product; t) the unit transportation cost between each pair of interacting network agents; $u$ ) the factory acquisition and production unit costs; v) each facility unit storage cost, and $\mathrm{x}$ ) the unit disposal cost; the goal is to determine 1) the network structure; 2) the production and storage levels: 3 ) the flow amounts; 4) the non-satisfied demand and return volumes, so as to minimize the global supply chain cost, minimize the environmental impact and maximize social benefit, in a solution of compromise. To achieve this solution of compromise the $\mathcal{E}$-constraint method is applied so as to obtain an approximation to the Pareto front.

\section{Case-study}

The model was applied to a case study where the supply chain of a Portuguese lead battery manufacturer company is to be optimized under economic, environmental and social concerns. This supply chain is composed by a factory in Oeiras (which is not to be relocated) and 12 rented warehouses spread over the country. Warehouses serve both as distribution and as direct sales points, serving around 2300 customers. The factory also acts as a warehouse. Given the strategic nature of this work, customers were clustered in 237 groups, according to their municipality. All customers' demands have to be fully satisfied and therefore no minimum limits are imposed on flows between warehouses and customers. The company has a recycling strategy implemented for endusage batteries and thus the supply chain comprises forward and reverse flows. Concerning transportation, for the inbound distribution (forward and reverse flows between the factory and warehouses) the vehicles are sub-contracted. The outbound distribution (forward and reverse flows between warehouses and customers) is exclusively performed by the company's vehicles.

The model was applied to this supply chain by considering a network super-structure of 1 factory, 237 costumers and 237 possible warehouses locations. Costumers' locations act also as possible warehouses' locations, however, a maximum number of 13 warehouses was considered, according to the company's strategy.

Table 1 and Figure 1 show the results obtained for each of the considered scenarios. The results show that a reduction of around $20 \%$ in total costs (having as basis the real case) can be achieved when minimizing cost. This is also true when minimizing environmental impact (the results presented are normalized environmental impacts). In fact, cost and environmental impact have a close to linear relation in this supply chain given the high environmental impact of warehouses and distances travelled (data not shown). However, this is not the case regarding social benefit (see Figure 1). 
Table 1. Results obtained for each scenario.

\begin{tabular}{lccrr}
\hline \multicolumn{1}{c}{ Scenario } & $\begin{array}{c}\text { Cost } \\
(€)\end{array}$ & $\begin{array}{c}\text { Normalized Environmental } \\
\text { Impact }\end{array}$ & $\begin{array}{c}\text { Social } \\
\text { Benefit }\end{array}$ & $\begin{array}{r}\text { Number of } \\
\text { warehouses }\end{array}$ \\
\hline Real & 2752445 & 1688741 & 116.9 & 13 \\
Min. Cost & 2215450 & 1687055 & 81.1 & 8 \\
Min. Environmental & 2216874 & 1686812 & 81.1 & 8 \\
Impact & 3564201 & 1885786 & 1621.4 & 13 \\
Max. Social Benefit & &
\end{tabular}
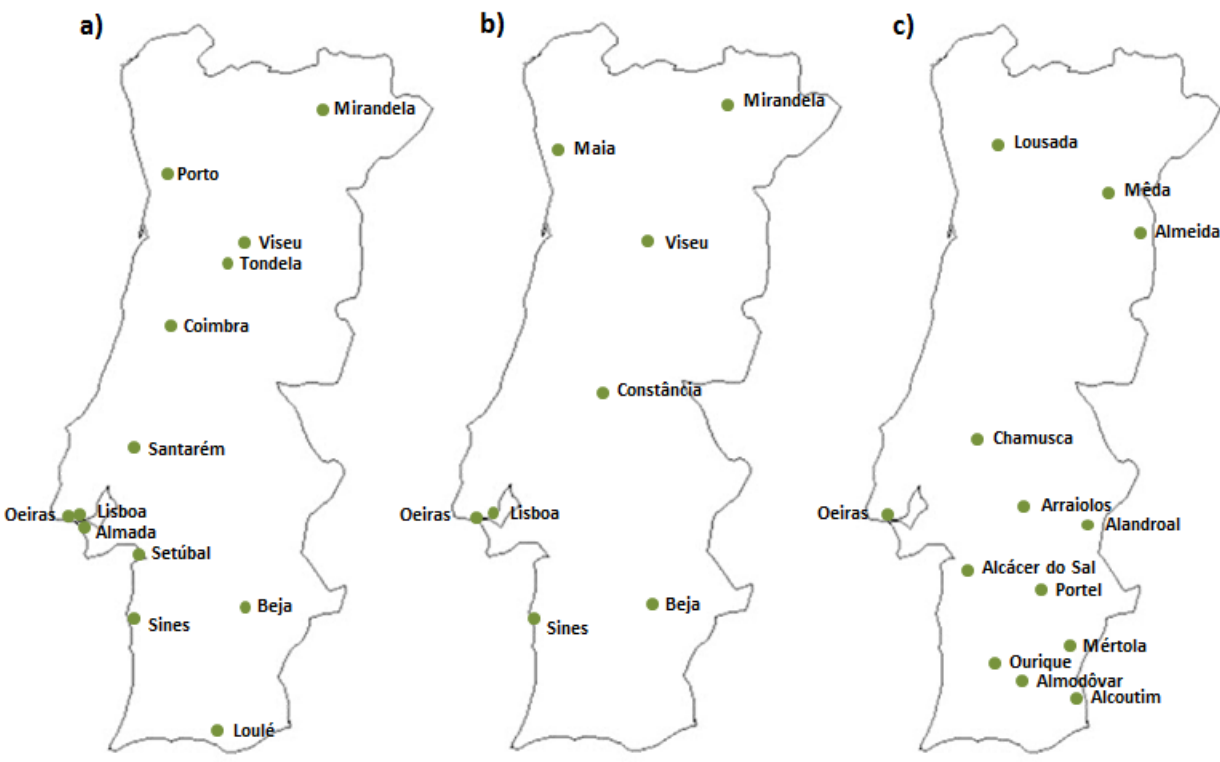

Figure 1. Location of warehouses for each scenario: a) real, b) minimizing cost (equal to minimizing environmental impact), and c) maximizing social benefit.

Population density was considered to obtain the regional factor, $\mu_{r}$, in equation 1 . This is justified by the fact that, in Portugal, coastal regions are much more developed and therefore much more populated than inland regions. The social benefit would then arise from job creation in the inland regions, which, in a bigger scale, would move people away from the overpopulated areas, increasing overall life quality. Figure 1 shows that when maximizing social benefit, the model prefers to locate warehouses in the region of Alentejo, which is indeed one of the less populated regions in Portugal. However, this scenario comes with an increase in costs of around $30 \%$ and an increase in environmental impact of around 12\% (which corresponds to an added emission of close to 6000 tonnes of $\mathrm{CO}_{2}$ equivalents to air).

Given these results, a multi-objective approach is necessary to obtain solutions of compromise. The $\mathcal{E}$-constraint method was then applied to obtain an approximation to the efficient frontier (Pareto front) that relates costs with social benefit which results are shown in Figure 2. 


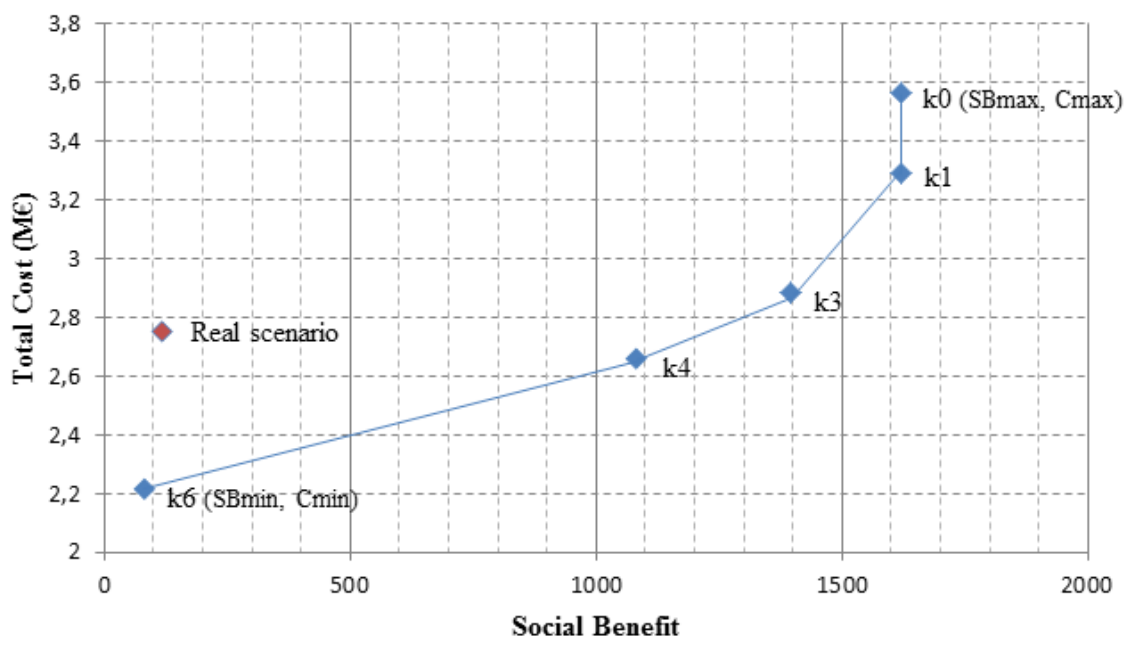

Figure 2. Approximation to the Pareto front obtained through the $\varepsilon$-constraint method ( $\mathrm{SB}-$ social benefit; $\mathrm{C}$ - costs).

It is clear that it is possible to obtain a very significant improvement in social performance at the cost of relatively small increases in cost. Furthermore, when comparing solution $\mathrm{k} 4$ to the real scenario, it is even possible to reduce costs (by $3.4 \%$ ), when compared to the real situation, while significantly increasing social benefit (around $825 \%$ ) with although an increase of $0.58 \%$ in environmental impact, Table 2.

Table 2. Results obtained for the real scenario and for solution $\mathrm{k} 4$ of the multi-objective approach.

\begin{tabular}{lccrr}
\hline Scenario & $\begin{array}{c}\text { Cost } \\
(€)\end{array}$ & $\begin{array}{c}\text { Normalized Environmental } \\
\text { Impact }\end{array}$ & $\begin{array}{c}\text { Social } \\
\text { Benefit }\end{array}$ & $\begin{array}{c}\text { Number of } \\
\text { warehouses }\end{array}$ \\
\hline Real & 2752445 & 1688741 & 116.9 & 13 \\
Solution k4 & 2659806 & 1698597 & 1081.3 & 11 \\
\hline
\end{tabular}

It should however be noted, as already mentioned, that the social benefit obtained from the developed indicator is not for the company itself but for the country. This is visible on the results presented in Table 2 where a much higher social benefit comes with fewer warehouses and therefore less overall job creation.

\section{Final Remarks}

This work proposes an optimization model for the design and planning of a closed loop supply chain under the three pillars of sustainability: economic, environmental and social sustainability. The environmental impact is assessed through ReCiPe 2008. A social benefit indicator was developed that favors job creation in less developed regions. The $\varepsilon$-constraint method is used to obtain the efficient frontier between economic and social performances and results show that significant improvements in the overall performance of the supply chain can be achieved.

As future work, it would be important to complement this study around the social benefit indicator with a quantitative evaluation of the improvement/decline in life 
quality that comes from job creation in a given region. Still this social benefit indicator could be used in designing government incentives for companies to locate their facilities in these preferred regions. Also, applying uncertainty in both internal (e.g. environmental and social performance) and external factors (e.g. demand) is intended.

\section{References}

A. Bojarski, J. Laínez, A. Espuña, L. Puigjaner, 2009, Incorporating environmental impact and regulations in a holistic supply chains modeling: An LCA approach, Computers \& Chemical Engineering, 33, 10, 1747-1759.

A. Brent, C. Labuschagne, 2006, Social indicators for sustainable project and technology life cycle management in the process industry, The International Journal of Life Cycle Assessment, 11, 1, 3-15.

J. Duque, A.P. Barbosa-Póvoa, A. Novais, 2010, Design and planning of sustainable industrial networks: application to a recovery network of residual products, Industrial \& Engineering Chemistry Research, 49, 9, 4230-4248.

M. Goedkoop, R. Heijungs, M. Huijbregts, A. Schryver, J. Struijs, R. van Zelm, 2009, ReCiPe 2008 - A life cycle impact assessment method which comprises harmonised category indicators at the midpoint and the endpoint level, The Hague: Ministry of VROM.

V. Guide, T. Harrison, L. Van Wassenhove, 2003, The challenge of closed-loop supply chains, Interfaces, 33, 6, 3-6.

G. Guillén-Gosálbez, I. Grossmann, 2009, Optimal design and planning of sustainable chemical supply chains under uncertainty, American Institute of Chemical Engineers Journal, 55, 1, 99121

A. Hugo, E. Pistikopoulos, 2005, Environmentally conscious long-range planning and design of supply chain networks, Journal of Cleaner Production, 13, 15, 1471-1491.

JRC, 2011, ILCD Handbook: Recommendations for Life Cycle Impact Assessment in the European context.

B. Ness, E. Urbel-Piirsalu, S. Anderberg, L. Olsson, 2007, Categorising tools for sustainability assessment, Ecological Economics, 60, 3, 498-508.

T. Pinto-Varela, A. P. Barbosa-Póvoa, A. Novais, 2011, Bi-objective optimization approach to the design and planning of supply chains: Economic versus environmental performances, Computers \& Chemical Engineering, 35, 8, 1454-1468.

M. Salema, A. P. Barbosa-Póvoa, A. Novais, 2010, Simultaneous design and planning of supply chains with reverse flows: A generic modelling framework, European Journal of Operational Research, 203, 2, 336-349.

C. Benoit, 2009, Guidelines for Social Life Cycle Assessment of Products, UNEP-SETAC. 